\title{
The cultural eutrophication of Lac la Biche, Alberta, Canada: a paleoecological study
}

\author{
D.W. Schindler, Alexander P. Wolfe, Rolf Vinebrooke, Angela Crowe, \\ Jules M. Blais, Brenda Miskimmin, Rina Freed, and Bianca Perren
}

\begin{abstract}
A multiproxy paleoecological investigation of Lac la Biche, a large boreal lake in northeastern Alberta, Canada, revealed that the lake was eutrophic before European settlement but has undergone additional cultural eutrophication in the past 30 to 50 years. Annual fluxes to sediments of phosphorus, nitrogen, carbon, and inorganic sediments have increased with time. A declining N-P ratio has increasingly favored nitrogen-fixing cyanobacteria. Increased deposition of microbial pigments and diatom frustules and a recent shift in diatom species also indicate increasing eutrophication. Biogenic silica increased with time, but there is no evidence of a near-surface decline that would indicate silica limitation. Stable isotopes suggest that an increasing proportion of carbon deposited in sediments is of in-lake origin, indicating increased productivity. In the basin nearest the town of Lac La Biche, an increase in $\delta^{15} \mathrm{~N}$ followed the construction of the sewage treatment plant, but more recently, decreased $\delta^{15} \mathrm{~N}$ in both basins suggests that nitrogen fixation has become a more important source of nitrogen. Despite documented damage to the fishery of the lake, zooplankton fossils do not show evidence of a strong trophic cascade. The study illustrates the power of a multiproxy approach in obtaining reliable paleolimnological conclusions.
\end{abstract}

Résumé : Une étude paléoécologique avec plusieurs variables de substitution au lac La Biche, un grand lac boréal du nord-est de l'Alberta, Canada, montre que le lac était eutrophe avant l'arrivée des européens, mais qu'il a subi une eutrophisation culturelle supplémentaire au cours des 30 à 50 dernières années. Les apports annuels aux sédiments de phosphore, d'azote, de carbone et de sédiments inorganiques se sont accrus au cours des années. Un rapport N-P en déclin a de plus en plus favorisé les cyanobactéries fixatrices d'azote. Les dépôts croissants de pigments microbiens et de frustules de diatomées, de même qu'un changement récent dans les espèces de diatomées, indiquent une intensification de l'eutrophisation. Il y a une augmentation dans le temps de la silice biogène, mais aucune indication d'un déclin près de la surface qui pourrait signaler une limitation de la silice. Les analyses d'isotopes stables laissent croire qu'une proportion croissante du carbone déposé dans les sédiments provient du lac lui-même, ce qui indique une productivité accrue. Dans le bassin versant le plus près de la ville de Lac-La-Biche, une augmentation de $\delta^{15} \mathrm{~N}$ a suivi la construction d'une usine de traitement des eaux usées; plus récemment, une réduction de $\delta^{15} \mathrm{~N}$ dans les deux bassins fait penser que la fixation d'azote est devenue une source plus importante d'azote. Malgré les données sur les dommages causés aux pêches dans le lac, les fossiles du zooplancton n'appuient pas l'existence d'une importante cascade trophique. Notre étude est un exemple du potentiel des méthodes à nombreuses variables de substitution pour l'obtention de conclusions paléolimnologiques fiables.

[Traduit par la Rédaction]

\section{Introduction}

Lakes of the prairie provinces generally occupy catchments rich in phosphorus, so that they tend to be mesotrophic or mildly eutrophic even without human interference (Prepas and Trew 1983). Iron concentrations in the lakes are usually low, even under anoxic conditions. As a result, periodic anoxia causes remobilization of phosphorus from sediments. Similar conditions have been observed to facilitate phosphorus release from sediments in other shallow calcareous lakes (Stauffer and Armstrong 1984; Stauffer 1985). This internal loading can be $50 \%$ to $90 \%$ of the total phosphorus loading to the lake (Prepas and Vickery 1984; Mitchell 2001). Such releases occur both under winter ice,

Received 14 August 2007. Accepted 2 April 2008. Published on the NRC Research Press Web site at cjfas.nrc.ca on 30 September 2008. J20137

D.W. Schindler ${ }^{1}$ and A. Crowe. Department of Biological Sciences, University of Alberta, Edmonton, AB T6G 2E9, Canada.

A.P. Wolfe. Department of Earth and Atmospheric Sciences, University of Alberta, Edmonton, AB T6G 2E3, Canada.

R. Vinebrooke. Freshwater Biodiversity Laboratory, Department of Biological Sciences, University of Alberta, Edmonton, AB T6G 2E9, Canada.

J.M. Blais. Department of Biology, University of Ottawa, Ottawa, ON K1N 6N5, Canada.

B. Miskimmin. Summit Environmental Consultants, 200-2800 29 Street, Vernon, BC V1T 9P9, Canada.

R. Freed. Gartner Lee Limited, 6400 Roberts Street, Suite 409, Burnaby, BC V5G 4C9, Canada.

B. Perren. Department of Geology, 22 Russell Street, University of Toronto, Toronto, ON M5S 3B1, Canada.

${ }^{1}$ Corresponding author (e-mail: d.schindler@ualberta.ca). 
Fig. 1. (a) Map showing the location of Lac la Biche in western Canada. (b) Map of Lac la Biche showing the location of the town by the same name, the inflows and outflows of the lake, rough morphometry, and other features. D1 and D3 are the locations of coring sites at the deepest spots in the basin nearest the town and the main basin of the lake, respectively. Shading represents depth in $5 \mathrm{~m}$ intervals, where the lightest shading represents $5 \mathrm{~m}$ and the darkest represents $20 \mathrm{~m}$.

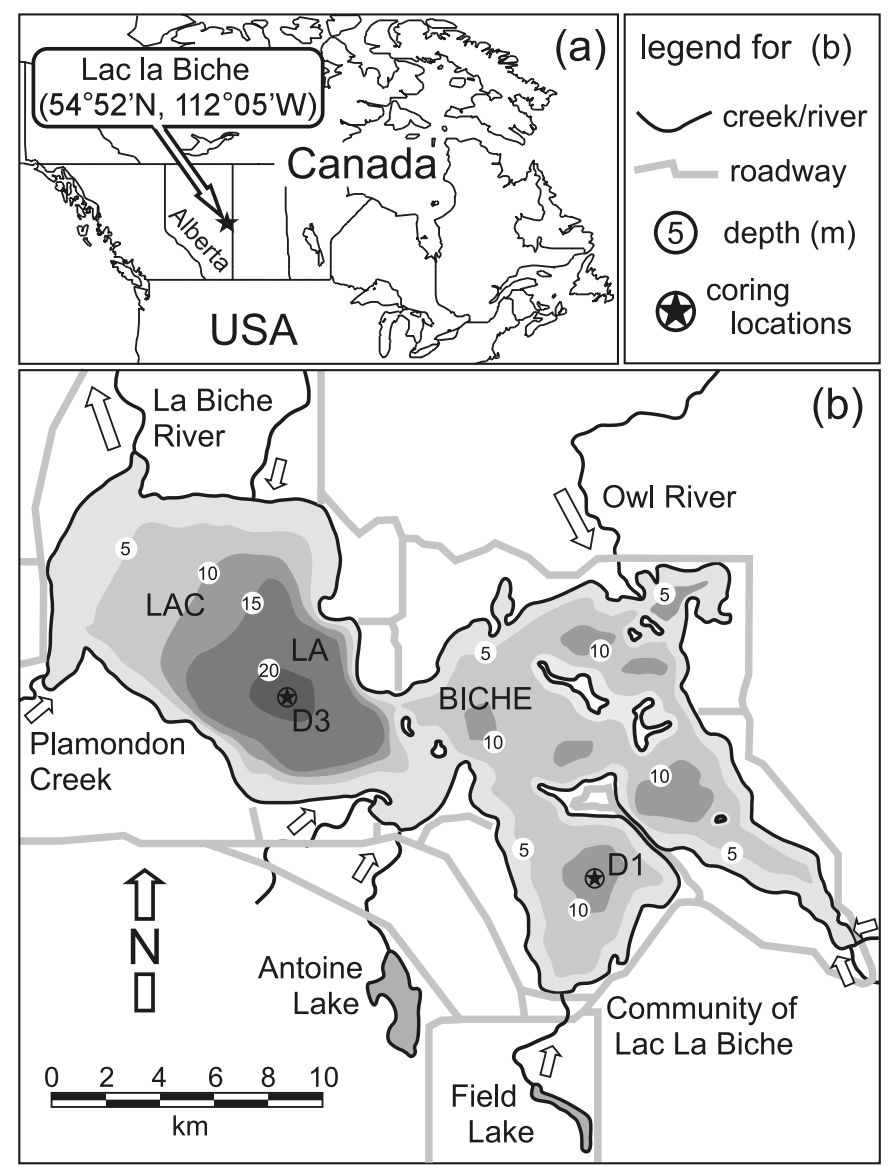

contributing to the magnitude of the spring algal bloom, and in midsummer, when they help to maintain high algal populations. During the latter period, there is usually a scarcity of inorganic nitrogen, favoring bloom-forming species of nitrogen-fixing cyanobacteria (Prepas and Trimbee 1988; D.W. Schindler, unpublished data).

The lakes are generally shallow and usually well mixed by the wind. However, during periods of low wind velocity, transient thermoclines develop rapidly. Anoxia develops quickly in the small hypolimnions, and in the absence of iron, large quantities of phosphorus are released to overlying water (Schindler and Comita 1972; D.W. Schindler, unpublished data). Such thermoclines form and break periodically throughout the summer season, allowing phosphorus in the euphotic zone to be replenished periodically, depending on weather conditions. The high variability in seasonal weather thus complicates the prediction of phosphorus concentrations and algal blooms in polymictic lakes. Stauffer and Armstrong (1984) concluded that similar polymictic conditions and periodic release of phosphorus from sediments were the
Table 1. Characteristics of Lac la Biche.

\begin{tabular}{ll}
\hline Elevation $(\mathrm{m})$ & 543.84 \\
Surface area $\left(\mathrm{km}^{2}\right)$ & 234 \\
Volume $\left(\mathrm{m}^{3}\right)$ & $1960 \times 10^{6}$ \\
Maximum depth $(\mathrm{m})$ & 21.3 \\
Mean depth $(\mathrm{m})$ & 8.4 \\
Shoreline length $(\mathrm{km})$ & 172 \\
Mean annual lake evaporation $(\mathrm{mm})$ & 702 \\
Mean annual precipitation $(\mathrm{mm})$ & 524 \\
Mean residence time (years) & 7 \\
Control structure & None \\
Terrestrial drainage $\left(\mathrm{km}{ }^{2}\right)$ & 4040 \\
Total nitrogen D1, D3 $\left(\mathrm{mg} \cdot \mathrm{m}^{-3}\right)$ & 860,846 \\
Total dissolved nitrogen D1, D3 $\left(\mathrm{mg} \cdot \mathrm{m}^{-3}\right)$ & 695,736 \\
Total phosphorus D1, D3 $\left(\mathrm{mg} \cdot \mathrm{m}^{-3}\right)$ & 97,68 \\
Total dissolved phosphorus D1, D3 $\left(\mathrm{mg} \cdot \mathrm{m}^{-3}\right)$ & 73,51 \\
Chlorophyll $a$ D1, D3 $\left(\mathrm{mg} \cdot \mathrm{m}^{-3}\right)$ & 16,10 \\
\hline
\end{tabular}

Note: Modified from Mitchell and Prepas (1990). Nutrient and chlorophyll $a$ concentrations are simple means of ice-free season data collected between 2003 and 2005 (D.W. Schindler, unpublished data).

reasons why Shagawa Lake, Minnesota, did not respond quickly to reductions in external nutrient loading.

Lac la Biche (Lake of the Red Deer, a translation of Waskisew Sagihaygan, the Cree name Elk Lake; Fig. 1) is a large $\left(234 \mathrm{~km}^{2}\right)$, shallow (mean depth $8.4 \mathrm{~m}$, maximum depth $22 \mathrm{~m}$ ) lake in northeastern Alberta. The lake is at a strategic portage between the Churchill and AthabascaMackenzie river systems and therefore has probably been occupied by aboriginal people for thousands of years. Key characteristics of the lake are given in Table 1.

For the past few decades, lakeshore residents have complained increasingly about poor water quality in the summer. There is a perception that nuisance blooms of cyanobacteria have intensified. A provincial study of the lake in 1990 concluded that there had been no deterioration in water quality, but this study was based on scarce data. In 2002, Lakeland County officials approached us to study the lake. Because of the shortage of historical data, we chose paleolimnological methods to assess past changes in water quality.

Lac la Biche exemplifies many of the lakes in the southern boreal and prairie parkland areas of Alberta in several ways, including the polymixis and low iron described above. Like other lakes in the area, its catchment has been subjected to extensive land clearing and agricultural activities in the past half century. A growing urban population in an affluent province has caused rapidly increasing concentrations of summer homes on the lakeshores.

Few of the lakes have been subjected to monitoring that is intense enough to reliably separate long-term trends in water quality from interannual variation. As a result, paleoecology could potentially provide useful information on the history of changes to many lakes of the region.

\section{A brief history of Lac la Biche}

The first known European settlement in the watershed was a Northwest Company trading post, Red Deer's Lake House, established on the southern shore of the lake by David Thompson in 1798. A Hudson's Bay Company (HBC) post, Greenwich House, the first HBC post beyond 
Rupert's Land, was established the following year by Peter Fidler. The Portage la Biche was the gateway to the southern Athabasca country from 1799-1824 and a passage to the Pacific coast from 1811-1824.

Métis settlements remained on the lake, and the Lac la Biche Mission on the shore of the lake was a popular gathering spot for religious or social events. A Cree settlement, the Beaver Lake First Nation, also has remained in the immediate area. There are several other aboriginal and Métis settlements in the region. The mission, now a historic site, still stands on the south shore of the lake.

The fishery of this productive lake was already heavily exploited in the 19th and 20th centuries (see supplementary material). ${ }^{2}$ By the end of the 20th century, the walleye (Sander vitreus) fishery had collapsed, and other fisheries are under stringent regulations.

Clearing of the watershed for agriculture began in the late 19th century and accelerated after World War II as modern tractors became available. In the mid-20th century, when reliable automobiles and improved roads resulted in increased tourism from populous cities in southern Alberta, the town began to grow. The population of the town of Lac La Biche in 2006 was listed as 2758, but the community is growing rapidly as the result of increasing recreational activity and development in the nearby Alberta Oil Sands. A small (300 people), French-speaking community, Plamondon, the only other community on the lake, is nestled in the valley of Plamondon Creek, which enters Lac la Biche at the western end of the lake.

Sewage began to be discharged into the lake in 1951 as the town of Lac la Biche constructed its first waste treatment plant. In 1983, the residents, who also drew their drinking water from the lake, decided that this posed too much of a threat to water quality. Sewage was diverted, discharging to Field Lake, upstream of Lac la Biche. Subsequent studies show that much of the sewage drains back to Lac la Biche via Red Deer Brook. Provincial agencies referred to the sewage as "growth-enhancing effluent" and regarded Field Lake as of marginal importance. The treatment plant was upgraded in 1989 but continued to discharge to Field Lake. A plan for a new treatment plant to remove nutrients or divert sewage from Field Lake is under discussion. A golf course along the southeastern shore of the lake is also a possible source of nutrients.

With continuous improvement in roads and increased population since the mid-20th century, recreational cottages have increased in number, largely along the southern shores of the lake. About $50 \%$ of the immediate catchment of the lake has been cleared for agriculture. Most is used as hayland or pasture, and there is little application of fertilizer.

By the early 1990s, residents of the area increasingly complained about water quality, particularly surface algal blooms and decreased clarity. Swimmer's itch, high fecal coliform counts near some beaches, and beach closures also became more common.

\section{Materials and methods}

On 1 February 2003, using a Glew gravity corer, we took short cores from the deepest locations in different basins of the lake. Subsequent limnological work showed that there was considerable similarity in the water quality at the three easternmost coring sites in the eastern part of the lake. Here we interpret the results of cores taken at the deepest points in the main (western) basin of the lake at site D3 $\left(54^{\circ} 50.049^{\prime} \mathrm{N}, 112^{\circ} 09.727^{\prime} \mathrm{W}\right)$ and in the basin nearest the town of Lac La Biche, which is the most eutrophic of the lake's basins, at D1 $\left(54^{\circ} 49.920^{\prime} \mathrm{N}, 111^{\circ} 55.838^{\prime} \mathrm{W}\right.$; Fig. 1). Cores were sliced at $0.5-1 \mathrm{~cm}$ intervals, dated by lead- 210 $\left({ }^{210} \mathrm{~Pb}\right)$ and analyzed for nutrients, algal fossils (diatoms and chrysophytes), dry weight, microbial pigments, biogenic silica, stable isotopes, and cladoceran remains. Sections were preserved for analysis in Whirl-Pak ${ }^{\circledR}$ bags and refrigerated. The depths at which cores were taken were $22 \mathrm{~m}$ at D3 and $9 \mathrm{~m}$ at D1. The cores analyzed were $45 \mathrm{~cm}$ (D3) and $50 \mathrm{~cm}$ (D1) in length, which included the entire period of recent changes in lake. We used methods that are widely accepted by the paleolimnological community for diagnosing changes in the trophic state of lakes (Douglas and Smol 1999; Riedinger-Whitmore et al. 2005; Schelske et al. 2006).

Dating using ${ }^{210} \mathrm{~Pb}$ analysis by gamma spectrometry was done at the University of Ottawa. Loss on drying, loss on ignition, total phosphorus, total nitrogen, biogenic silica, and stable isotope analyses were conducted in the Limnology Laboratory in the Department of Biological Sciences at the University of Alberta. Diatom analyses were performed at the Department of Earth and Atmospheric Sciences, and pigments were analyzed in the Freshwater Biodiversity Laboratory, both at the University of Alberta (Edmonton, Alberta).

Diatom slides were prepared from 25 samples in core D1 and from 27 samples in core D3, with greater sampling density towards the surface. In each case, $200 \mu \mathrm{g}$ of freezedried sediment was boiled progressively in $10 \%$ and $30 \%$ $\mathrm{H}_{2} \mathrm{O}_{2}$. Cleaned and diluted slurries were spiked with a known quantity of Eucalyptus pollen grains to enable quantitative assessments of diatom concentrations (Wolfe 1997). Diatom sums ranged from 300 to 500 valves per sample. Chrysophyte stomatocysts were also counted, but no effort was made to differentiate them taxonomically. Preservation was poor in all but the upper $7 \mathrm{~cm}$ of the D1 core but was good for the entire length of core D3. Diatom taxonomy was assisted by regional western Canadian floras (Cumming et al. 1995; Moser et al. 2004), augmented by other sources (Patrick and Reimer 1966, 1975; Krammer and Lange-Bertalot 1986-1991). Diagrams of diatom and chrysophyte stomatocyst concentrations alongside sediment biogenic silica and of down-core assemblage composition expressed as frequencies relative to the sum counted are shown.

Microbial pigment concentrations were quantified using a standard reverse-phase high-pressure liquid chromatographic technique (HPLC; Vinebrooke et al. 1998). Pigments were

\footnotetext{
${ }^{2}$ Supplementary data for this article are available on the journal Web site (http://cjfas.nrc.ca) or may be purchased from the Depository of Unpublished Data, Document Delivery, CISTI, National Research Council Canada, Building M-55, 1200 Montreal Road, Ottawa, ON K1A 0R6, Canada. DUD 3825. For more information on obtaining material refer to http://cisti-icist.nrc-cnrc.gc.ca/cms/unpub_e.html.
} 
Fig. 2. Cumulative unsupported ${ }^{210} \mathrm{~Pb}$ (dates based on the constant rate of supply (CRS) model) and dry mass accumulation of sediment at (a) site D1 and (b) site D3 in Lac la Biche. Cores D1 and D3 were 42 and $50 \mathrm{~cm}$ long, respectively.

(a)

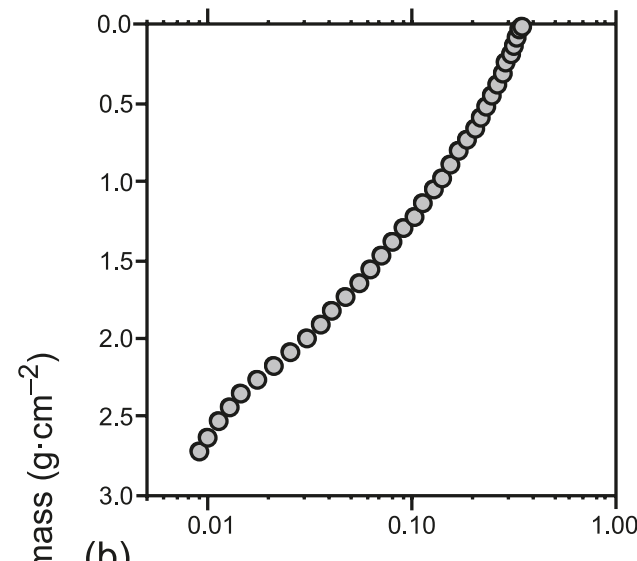

(b)
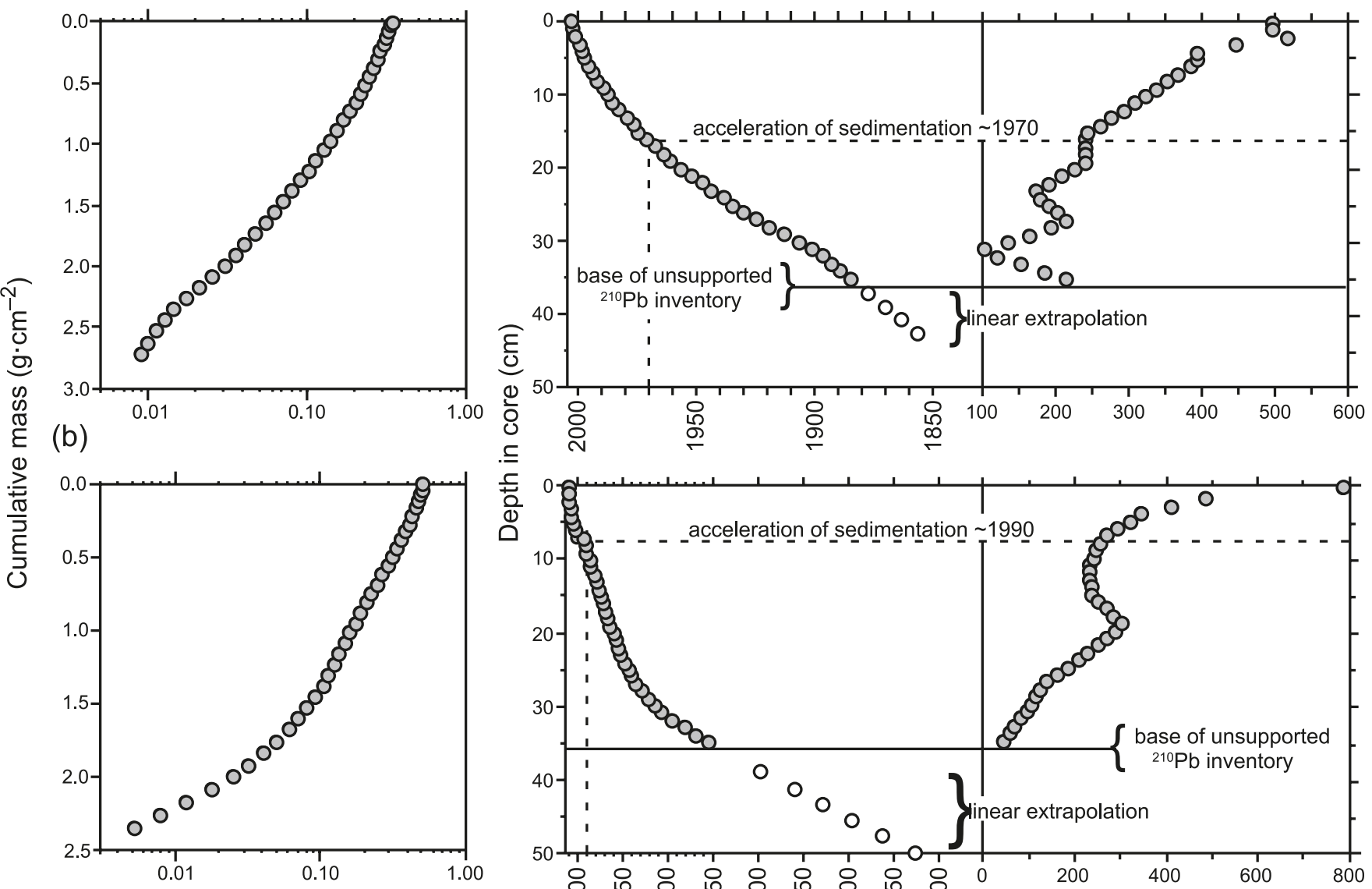

Cumulative unsupported ${ }^{210} \mathrm{~Pb}$ $\left(\mathrm{Bq} \cdot \mathrm{cm}^{-2}\right)$

first extracted from freeze-dried sediments using an acetone-methanol solution. Extracts were then filtered (0.2 $\mu \mathrm{m}$ pore nylon), dried under $\mathrm{N}_{2}$, and reconstituted using a precise volume of injection solution. Chromatographic separation was performed with an Agilent 1100 Series HPLC (Agilent Technologies Canada Inc., Calgary, Alberta) equipped with a Varian Microsorb $100 \mathrm{C} 18$, and pigment was detected using in-line diode array and fluorescence detectors. Pigment concentrations were quantified via calibration equations and an electronic spectral library of standards purchased from DHI Water and Environment (Agern Alle 5, DK-2970 Hoersholm, Denmark).

Sediments for biogenic silica (BSi) analysis were predigested according to Mortlock and Froelich (1989) and analyzed using the wet alkaline method of Conley and Schelske (2001). Briefly, $30 \mathrm{mg}$ of sediment was predigested with $10 \% \mathrm{H}_{2} \mathrm{O}_{2}$ for $30 \mathrm{~min}$ followed by $1 \mathrm{~mol} \cdot \mathrm{L}^{-1}$ $\mathrm{HCl}$ for an additional $30 \mathrm{~min}$ to disaggregate the sediment. Subsequently, $20 \mathrm{~mL}$ of deionized water was added and the samples were centrifuged at $4300 \mathrm{~g}$ for $5 \mathrm{~min}$. The supernatant was decanted and samples were dried overnight at $60{ }^{\circ} \mathrm{C}$. Samples were subsequently incubated with $40 \mathrm{~mL}$ of $1 \% \mathrm{Na}_{2} \mathrm{CO}_{3}$ in a shaker bath at $85{ }^{\circ} \mathrm{C}$ and $100 \mathrm{r} / \mathrm{min}(1 \mathrm{r}=$
$2 \pi \mathrm{rad})$. Supernatant was subsampled after 3,4 , and $5 \mathrm{~h}$ and analyzed for molybdate-reactive silicon using a Technicon AutoAnalyzer II according to standard methods at the Limnological Services Unit at the University of Alberta. Si concentrations at each of the three sampling periods were averaged to infer BSi concentrations at zero time.

For fossil cladocerans, $1 \mathrm{~mL}$ of sediment per interval was added to $15 \mathrm{~mL} 10 \% \mathrm{KOH}$, gently heated, and occasionally swirled for $5 \mathrm{~h}$. Supernatant $\mathrm{KOH}$ was decanted and the sediments were diluted at least three times with distilled water. The final volume was brought to either 5 or $10 \mathrm{~mL}$ and subsampled to slides ( $50 \mu \mathrm{L}$ per slide) using glycerine jelly stained with lignin pink as a mounting medium (Hann 1989). A phase-contrast microscope was used to identify and enumerate cladoceran remains from four slides $(200 \mu \mathrm{L})$ or until total remains exceeded 150 per sample. Remains included postabdominal claws (daphnids), head shields, or carapaces (bosminids and chydorids). Data are reported as number of remains per milligram of dry sediment mass.

Nitrogen and carbon stable isotope ratios were determined by analyzing about $3 \mathrm{mg}$ of sediment with a continuous-flow isotope ratio mass spectrometer (IRMS) using a GV Instruments IsoPrime mass spectrometer with a EuroVector 
Fig. 3. Concentrations of carbon, nitrogen, and phosphorus as percent of dry mass and the molar ratios of nutrients vs. CRS dates at (a) site D1 and $(b)$ site D3. In this and subsequent figures, dates before 1880 are extrapolated and are given only to show the relatively constant conditions before 1900. Note the varied scaling on $x$ axes of the panels.

(a)

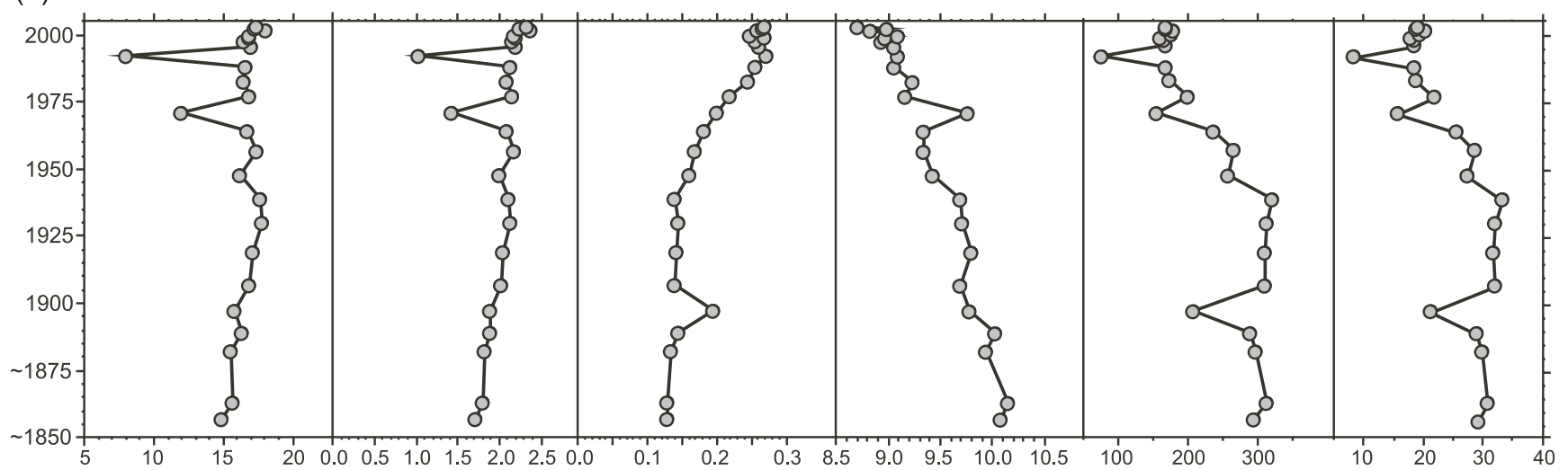

(b)

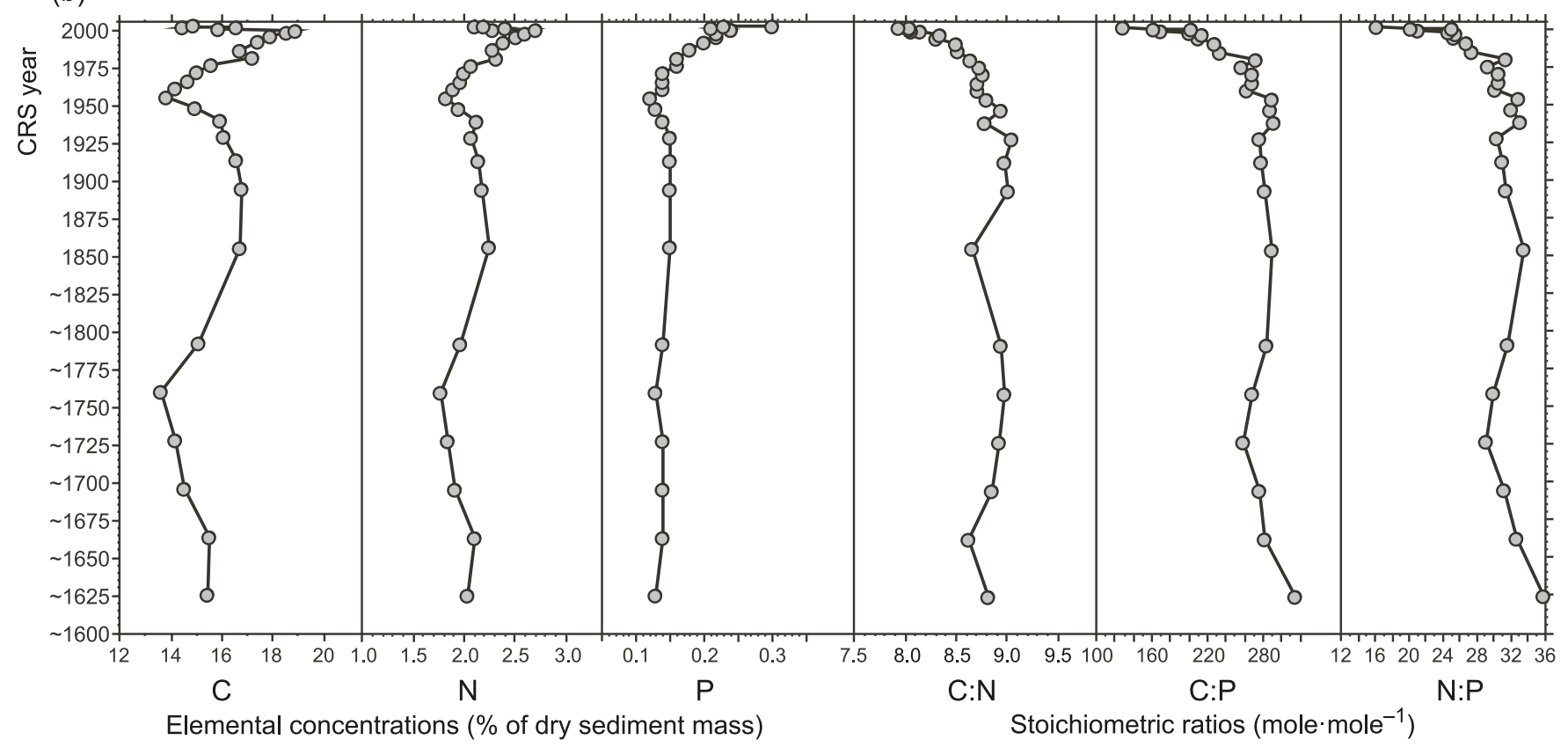

EuroEA3028-HT elemental analyzer. Analysis was performed at the Limnological Services Unit, University of Alberta. All nitrogen isotopic results are expressed in conventional $\delta$ notation relative to air as $\delta^{15} \mathrm{~N}=\left(R_{\text {sample }} /\right.$ $\left.R_{\text {standard }}-1\right) \times 1000$, where $R$ is the ratio of measured ${ }^{15} \mathrm{~N}$ to ${ }^{14} \mathrm{~N}$. A similar equation was used for calculating $\delta^{13} \mathrm{C}$, using PeeDee dolomite as a standard.

\section{Results}

The length of the cores extended well beyond the period when reliable ${ }^{210} \mathrm{~Pb}$ dates could be applied (1850 to the present). Before 1850, dates are assigned by linear extrapolation, which has the potential for considerable error. Dates are presented to show the long-term, relatively uniform deposition of nutrients and other indicators before the 20th century.

Sediment cores from both basins of the lake showed accelerated sedimentation in the latter half of the 20th century. At D1, most of the increase occurred after about 1970, increasing linearly to values in the past few years that are approximately double those in 1970 (Fig. 2). At D3, the increase began later, about 1990, but increased exponentially after that date to values two to three times higher than rates earlier in the 20th century.

Concentrations of carbon, nitrogen, and phosphorus were originally high. These and pigment and diatom analyses presented below indicate that the lake was eutrophic before European settlement. However, all nutrients increased during the latter part of the 20th century in both cores, providing evidence of increasing production and eutrophication (Fig. 3). At D1, the increase in carbon and nitrogen was slow and gradual in the early 20th century. The increase in phosphorus accelerated after about 1930. At D3, all three elements began to increase in the last few decades. The ratios of $\mathrm{C}$ to $\mathrm{N}, \mathrm{C}$ to $\mathrm{P}$, and $\mathrm{N}$ to $\mathrm{P}$ decrease in both cores in recent decades, indicating the greater increase in phosphorus than in carbon or nitrogen. The ratio of $\mathrm{N}$ to $\mathrm{P}$, usually critical to the dominance of cyanobacteria, decreased from background values of 30:1 or greater (molar ratio) to 
Fig. 4. Annual flux of phosphorus, organic matter, and inorganic matter to sediments $\left(\mathrm{g} \cdot \mathrm{m}^{-2} \cdot \mathrm{year}^{-1}\right)$ at $(a)$ site D1 and $(b)$ site D3 in Lac la Biche.
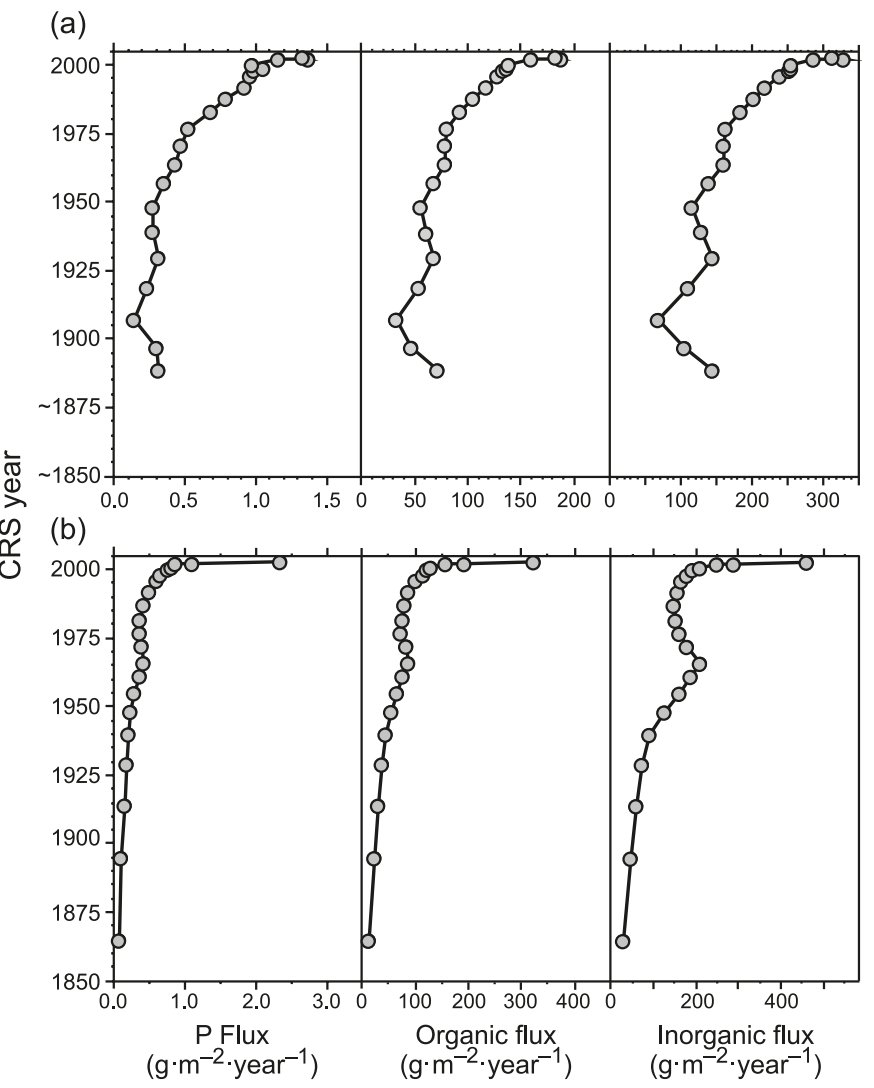

recent values of less than 20:1 in D1 and 16:1 in D3 (Fig. 3).

When nutrient concentrations and sedimentation rates are combined to calculate the nutrient fluxes to sediments, it is clear that annual deposition of phosphorus, organic matter, and inorganic matter have increased exponentially (Fig. 4). At D1, recent fluxes are about five times those in 1950. At D3, there was a slow increase in phosphorus flux during the period of record, which has accelerated since about 1990.

Together, these figures indicate a number of changes occurring during the 20th century. (i) There is an increase in soil entering the lake basin by erosion, probably bringing with it phosphorus bound to soil particles. Such erosion is very visible in areas around the lake where land uses are changing, lakeshore development is occurring, roads, pipelines, and housing sites are cleared, etc. (ii) After 1950, the increase in phosphorus in core D1 cannot be accounted for by erosion alone, suggesting that there are also other sources of the element. The timing of the increase suggests that sewage from the town is the most likely cause, although lakeshore development and land clearing cannot be ruled out. The increase in phosphorus at D3 occurred about 20 years later. It most likely results from cottage development, land clearing, manure from pastures, fertilizer from cultivated lands, and perhaps sewage discharge from the growing community at Plamondon (D.W. Schindler, unpublished data). Typically, phosphorus from manure, fertilizer, and sewage is much more available to algae than that from land clear- ing, which is usually largely bound into clay minerals. All of the sources are common problems associated with human development, and their influence has been documented at many locations in Europe and North America (Jeppesen et al. 2000; Schindler 2006).

Analyses of microbial (cyanobacteria plus algae) pigments showed that total algal abundance has increased over time in both lake basins (Fig. 5). Total chlorophyll concentrations were several-fold greater in sediments deposited since 1960, represented by sediments in the upper $20 \mathrm{~cm}$ of each core. However, an important caveat involving this finding is that pigments typically degrade somewhat in the upper layers of lake sediments. The stratigraphy of the chlorophyll-pheophytin ratio suggested that degradation of labile pigments was confined mainly to the uppermost $5 \mathrm{~cm}$ of both cores. Therefore, we remain confident that total algal abundance has increased during the latter half of the 20th century. All total chlorophyll values were comprised solely of isomers of chlorophyll $a$, which indicated a high abundance of cyanobacteria and the relative lack of other algal groups that are also capable of producing chlorophylls $b$ and $c$.

Taxonomically diagnostic carotenoids showed that distinct compositional changes occurred recently in the phytoplankton community, primarily involving certain groups of cyanobacteria (Fig. 5). The presence of several diagnostic pigments (zeaxanthin, canthaxanthin, echinenone) revealed that cyanobacteria were the most common and diverse group of phytoplankton in the lake, even before European settlement. In particular, zeaxanthin levels remained relatively high and constant throughout both cores. In comparison, the canthaxanthin-inferred abundance of filamentous cyanobacteria showed a more striking increase since 1950. Recent declines in the cyanobacterial pigment echinenone in D3 suggest that certain deepwater benthic or benthic filamentous taxa have become less abundant.

Pigment profiles suggest that the abundance of other algal groups has also increased in Lac la Biche over the past few decades (Fig. 5). Diatoms have shown a gradual net increase in abundance over the past few decades as indicated by higher concentrations of diatoxanthin and fucoxanthin in the upper parts of both cores. However, rapid down-core declines in fucoxanthin levels can be partly attributed to poor preservation of this labile pigment. Higher concentrations of the cryptophycean pigment alloxanthin in the top sediment intervals of both cores further suggests that phytoflagellates have become more abundant in Lac la Biche.

Siliceous fossils also indicate that the lake was originally eutrophic, but production of silicious algae has increased in recent years (Fig. 6). The total concentration of diatom valves, chrysophyte cysts, and biogenic silica all increase in upper parts of the core.

Diatom valves are well preserved in the deeper core (D3) in contrast to the shallower core (D1), more proximal to the town site, where preservation is poor (Fig. 6). The reason for spatial heterogeneity of diatom preservation remains unclear, but it is suspected that highly alkaline pore waters have developed in the sediments deposited at D1, leading to the intensified dissolution of biogenic silica. The legacy of silica dissolution at D1 is further evidenced by much lower diatom, chrysophyte, and biogenic silica concentrations rela- 


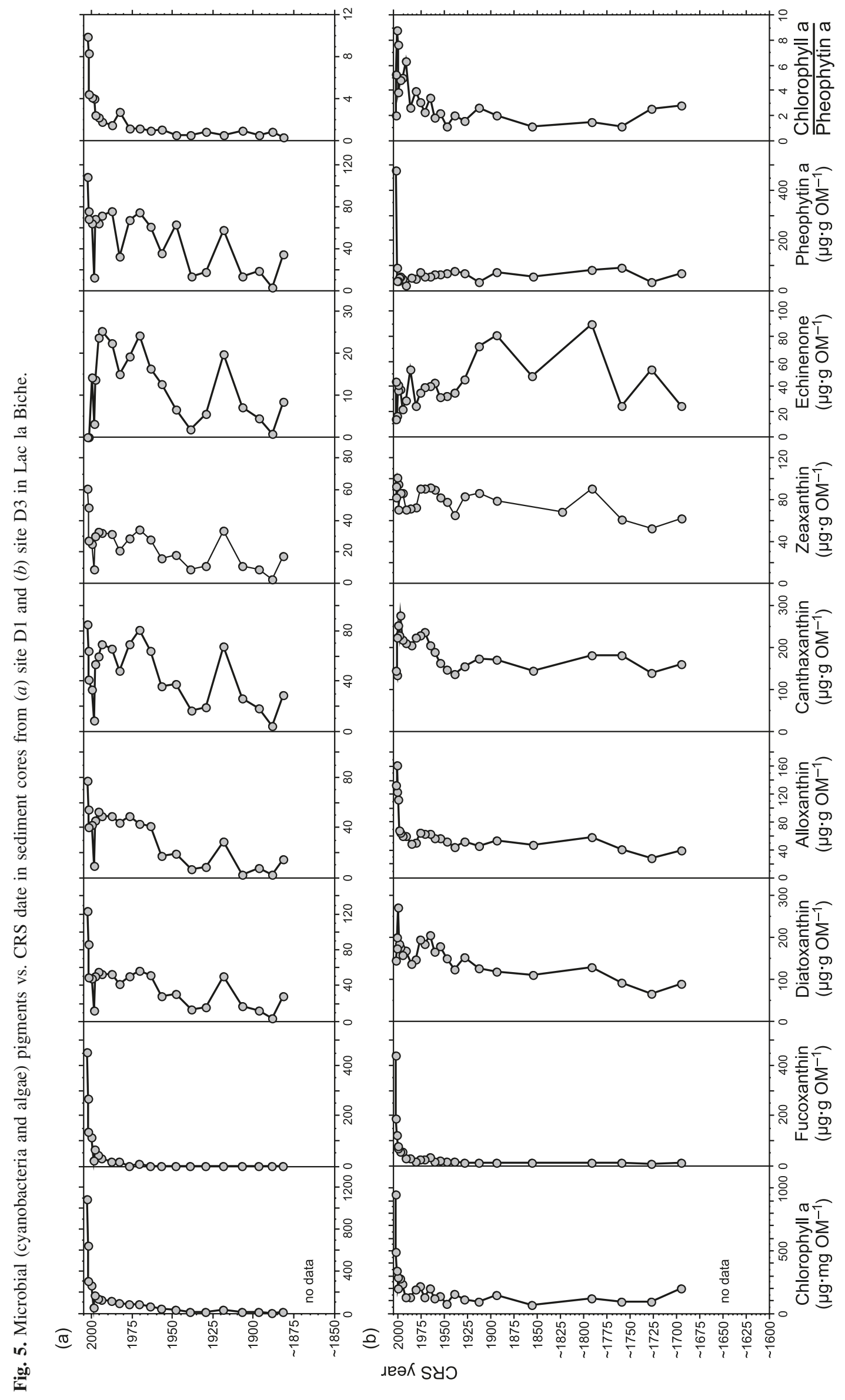

(C) 2008 NRC Canada 
Fig. 6. The number of diatom valves and chrysophycean cysts and the concentration of biogenic silica vs. CRS dates at (a) site D1 and (b) site D3 in Lac la Biche.

\section{(a)}

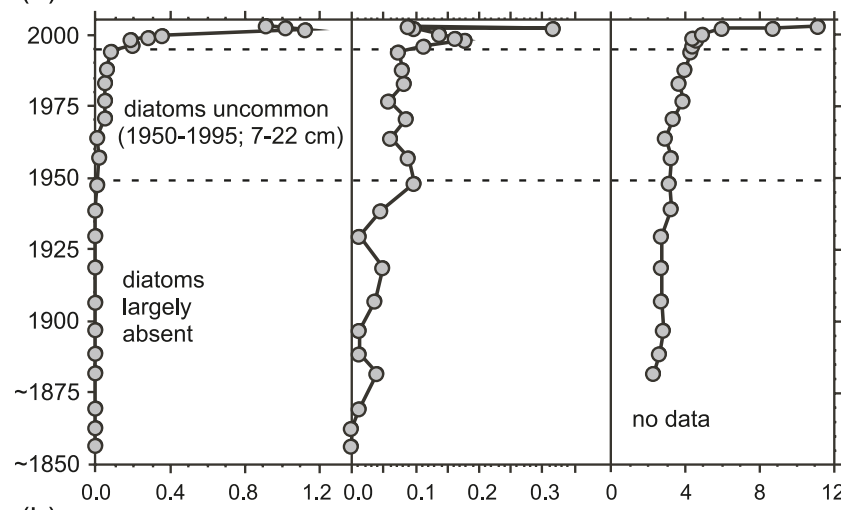

(b)

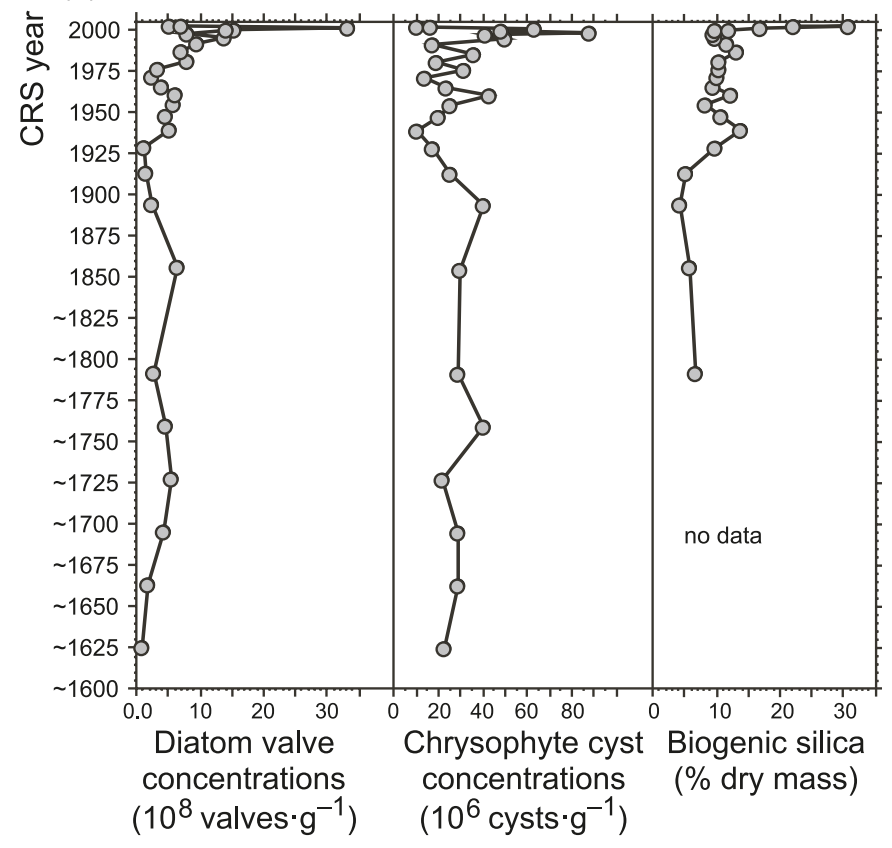

tive to the core from D3 (Fig. 6). Because of the uncertainties surrounding the diatom record from the shallower site, emphasis is placed on the record from D3, which appears to capture primary features of recent ecological change.

The diatom flora from Lac la Biche is strongly dominated by mesotrophic to eutrophic planktonic taxa belonging to the genera Aulacoseira, Cyclotella, Fragilaria, and Stephanodiscus. The prevalence of planktonic diatoms is probably in part due to the D3 coring site being much deeper than the depth of the euphotic zone and several kilometres from areas that are shallow enough to support benthic photosynthesis. In core D3, benthic taxa never account for more than $15 \%$ of assemblages, and typically represent $<5 \%$ (Fig. 7). Historically (i.e., pre-1850), the lake was dominated by $C y$ clotella bodanica and Stephanodiscus minutulus, indicating a moderately productive, but never hypereutrophic, lake regime. Beginning around 1910, diatom assemblages began to shift towards larger (Stephanodiscus niagarae) and more heavily silicified (Aulacoseira granulata) forms. This change is accompanied by increased frequencies of plank- tonic fragilarioid species (Fragilaria crotonensis and, to a lesser extent, Fragilaria capucina), together indicating a slight increase of lake production. Biogenic silica doubled around this time (Fig. 6). A second floristic reorganization occurred around 1990, when populations of A. granulata and small Stephanodiscus spp. decreased, displaced by $S$. niagarae and planktonic Fragilaria spp. This change is also reflected by several-fold increases of total diatom and chrysophyte cyst concentrations, as well as a dramatic increase in sediment biogenic silica content (Fig. 6) and the carotenoids specific to these algae (Fig. 5).

Given the available autecological data for these taxa in relation to human disturbance (Bradbury 1975; Cumming et al. 1995) and the wealth of corroborating limnological and paleolimnological data from analyses presented above and otherwise available (D.W. Schindler, unpublished data), the diatom changes expressed in Lac la Biche sediments are viewed as a first-order response to $\mathrm{P}$ enrichment in the $\mathrm{ab}$ sence of attendant Si limitation.

Fossil cladocerans (Crustacea) were analyzed only in the core from D3. Their remains showed rather consistent increases in fluxes of Daphnia galeata to sediments over time (Fig. 8). This is a small species of daphnid that is not a strong grazer, therefore usually not involved in community changes that affect algal abundance enough to cause a trophic cascade. Occasional postabdominal claws of larger Daphnia species were found, but there was no consistent pattern over time. Bosmina fossils increased from absent or very rare in the late 19th century, peaking around 1950, then decreasing slightly after that time. Bosmina are among the few zooplankton capable of feeding on cyanobacteria, and their increase is likely to be a consequence of the increased eutrophication of the lake. There were similar slow increases in Chydorus and total cladoceran remains (Fig. 8). Together, these increases roughly parallel observed increases in nutrients, diatom concentrations, and species shifts and the abundance and distribution of pigments and probably represent the overall increase in productivity of the lake.

Changes in stable isotopes with time indicate some important differences between the basins (Fig. 9). In both cores, $\delta^{13} \mathrm{C}$ was very similar, becoming much lighter since about 1950, as expected if algal photosynthesis was responsible for an increasing proportion of carbon stored in sediments. The slight reversal of this trend since about 1975 may be due to increased inputs of allochthonous materials resulting from land clearing or lakeshore development. In the past few years, the extreme trend toward heavier carbon may be because ratios have not yet stabilized as the result of postdepositional decomposition.

In contrast, nitrogen isotope signals differed greatly between the two basins. At D1, $\delta^{15} \mathrm{~N}$ became heavier after 1950, as would be expected from the increased input of human sewage due to the construction of the wastewater treatment plant, where denitrification typically causes losses of lighter nitrogen isotopes to the atmosphere. It is noteworthy that $\delta^{15} \mathrm{~N}$ in sediments did not become lighter at the time when the sewage was diverted to Field Lake in the early 1980s, supporting our observation that nutrients from sewage still reached Lac la Biche via Red Deer Brook, the outlet of Field Lake. The strong trend toward a lighter signal in the 1990s may reflect the drought conditions in recent 

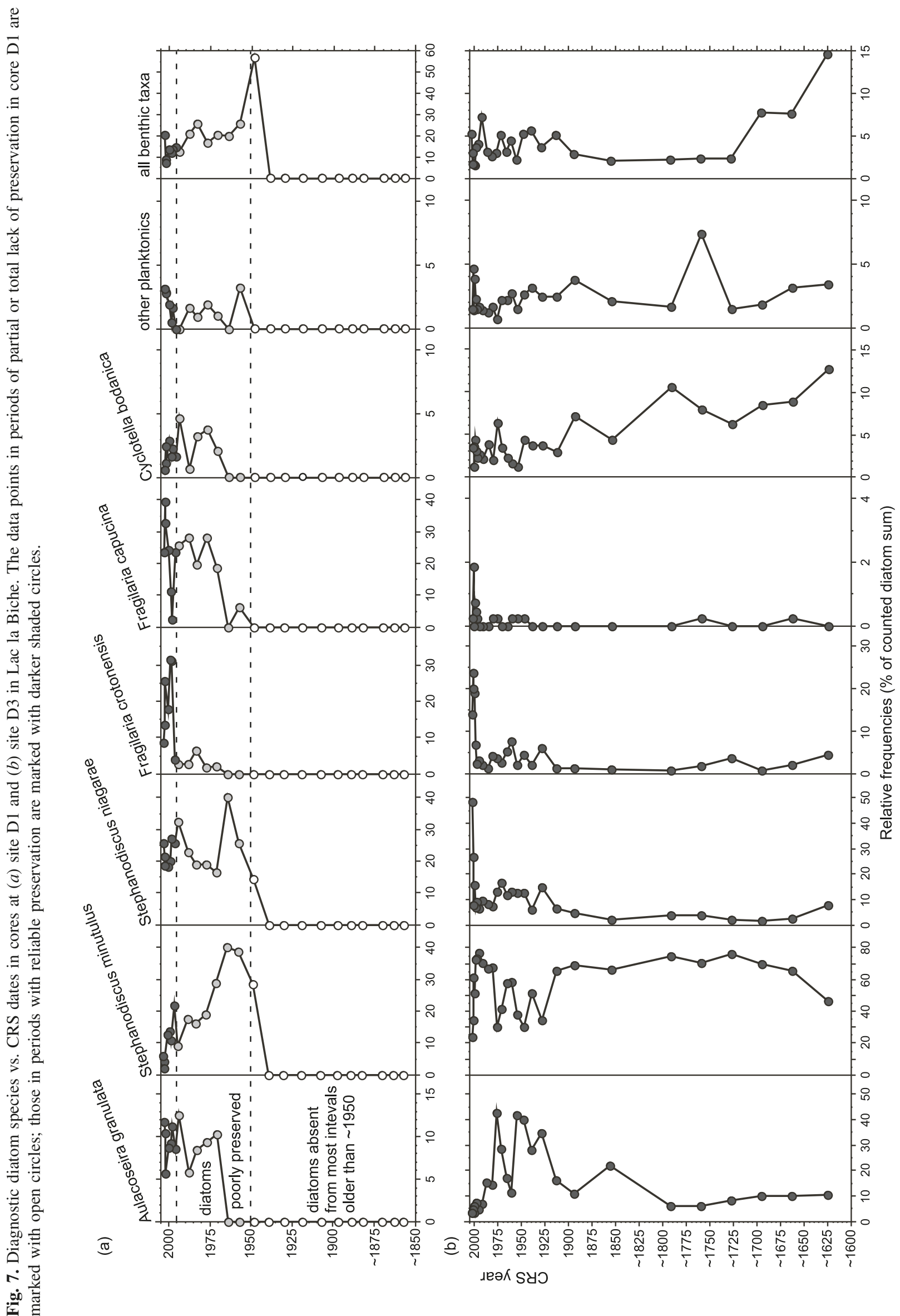
Fig. 8. Changes in fluxes of the most predominant cladoceran zooplankton in core D3.

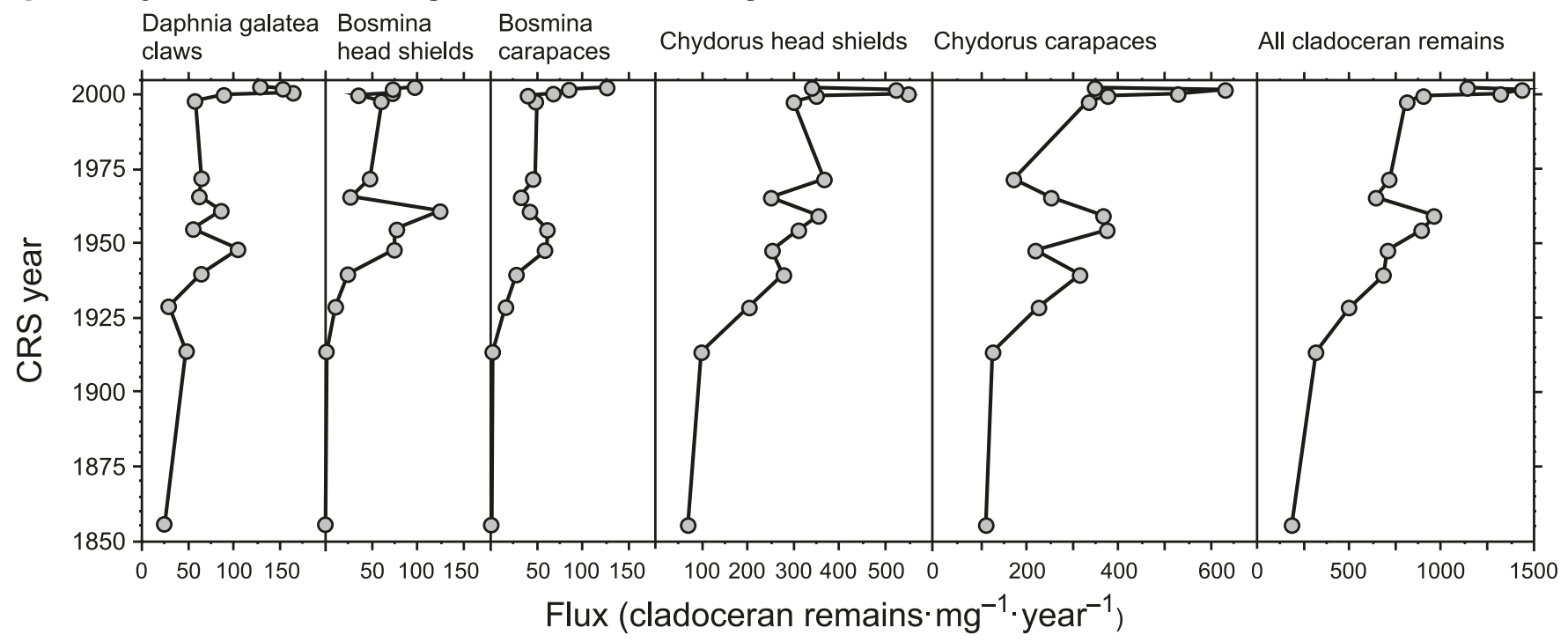

Fig. 9. $\delta^{13} \mathrm{C}$ and $\delta^{15} \mathrm{~N}$ vs. CRS dates in sediment cores at $(a)$ site D1 and (b) site D3 in Lac la Biche.

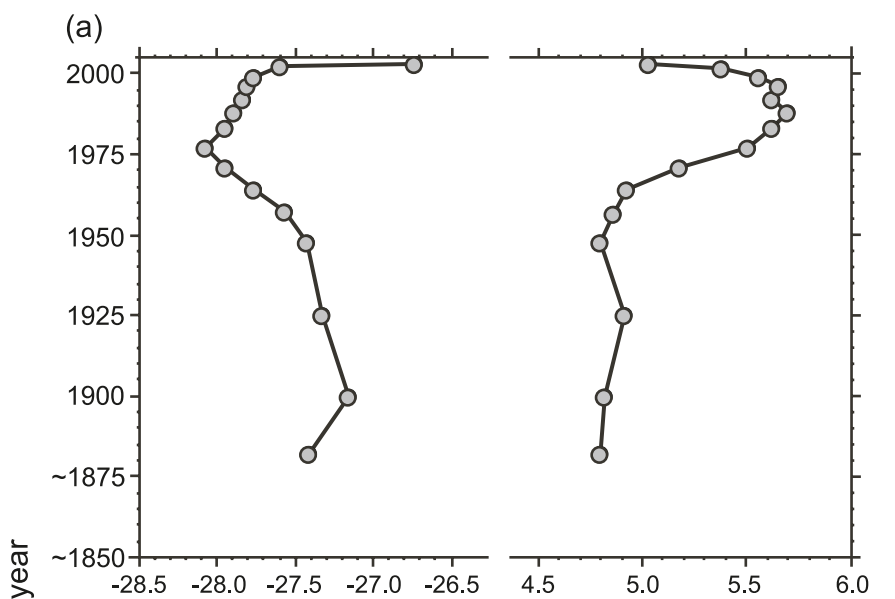

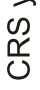
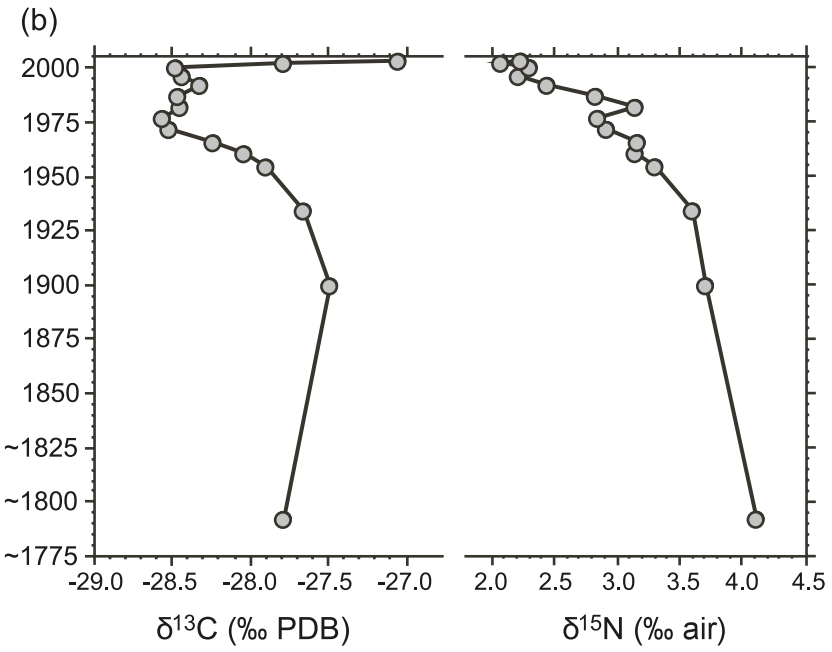

years, with very low flows in Red Deer Brook and other tributaries to D1, coupled with rapidly increasing abundance of nitrogen-fixing species.

In basin D3, where most human sewage is disposed of via septic tanks, there is no evidence of a heavier nitrogen signal. Instead, there is a continuing trend toward lighter nitrogen, probably reflecting the increasing importance of nitrogen-fixing cyanobacteria that residents of the area have observed.

\section{Discussion}

Taken together, our results confirm the observations of local residents that algal blooms, particularly of nuisance cyanobacteria, have increased in Lac la Biche for the past two to three decades and are intensifying. Increased accumulation rates of phosphorus and microbial pigments indicate that eutrophication accelerated in the basin nearest the community of Lac La Biche (site D1) after about 1950 and in the main basin of the lake (site D3) after 1970. Eutrophication was also demonstrated by increases in diatom numbers and in biogenic silica deposition and by a shift toward diatom species indicative of more productive conditions.

Increased annual fluxes of inorganic matter indicate that erosion in the catchment of the lake has also increased. Local soils contain apatite, and erosion is partly responsible for the nutrient increases in sediments, especially early in the 20th century. Such changes are commonly observed when forested land is changed to agricultural or urban uses, when roads are built, and when cottage development causes erosion near the lakeshore. All of these happened in the Lac la Biche catchment. After the mid-20th century, increased concentrations of phosphorus and nitrogen indicate that human sewage and (or) animal manure are likely additional nutrient sources. The $\mathrm{N}-\mathrm{P}$ ratios of sewage and manure are typically $<4: 1$ by weight, causing the decline in $\mathrm{N}-\mathrm{P}$ ratios in sedimented material in recent years. The declining $\mathrm{N}-\mathrm{P}$ ratio over time indicates that nutrient conditions have become increasingly favourable for nitrogen-fixing cyanobacteria, species that are commonly associated with nuisance blooms of algae.

Biogenic silica does not decline to near zero before 1950 in core D1, despite the poor preservation of diatoms. We believe that the high background of biogenic silica is the result 
of the decay of microfossils such as sponge spicules, phytoliths, and gemmoscleres in D1. Also, chrysophycean stomatocysts and siliceous protozoan plates were still abundant in these older sediments. Also, although identifications were not possible, some diatom fragments were still found at the base of the core. It should also be recognized that the alkali treatment in the analysis for biogenic silica represents a compromise between complete dissolution of biogenic compounds and the beginning of an attack and solubilization of clay minerals. Inorganic phytosilicates may also be dissolved by the technique. In short, we expect that the method would show a background above zero even when recognizable diatom frustules are not present.

Preliminary evidence from the fossil Cladocera suggests that disrupted trophic relationships as the result of declining populations of walleye (Sander vitreus) and other predators has probably not played a large role in the eutrophication of the lake. If such a "trophic cascade" had been initiated by the heavy fishing pressure that is known to have occurred, Daphnia numbers should have declined during the 20th century. Instead, there is a slow increase in the flux of Daphnia remains, which is probably the result of a general increase in phytoplankton during the period. In view of the documented human travel through the area, the appearance of Bosmina in the early 20th century may have been an accidental introduction from other lakes. Both Bosmina and Chydorus also increased slowly over time. The most plausible explanation for the observed pattern is that all cladoceran taxa responded to the increasing productivity of the lake.

The constant rates of deposition of sediments and of chemical and biological proxies in the period before 1900 indicate that it is unlikely that the small aboriginal population and the early period of European settlement were responsible for eutrophication of Lac la Biche. Most proxies began to change in consistent ways early in the 20th century, during the period when land clearing in the basin began, the result of increased influx of European settlers. All proxies indicate that eutrophication accelerated greatly in the latter part of the 20th century, when land clearing increased, summer cottage development accelerated, and waterborne disposal of sewage began, as described in the Introduction.

It is not a new discovery that many lakes of the prairie provinces were naturally eutrophic. Hickman and Klarer (1981) and Forbes and Hickman (1981) had reached similar conclusions for Lake Isle and Lac Ste. Anne, and Hickman et al. (1984) had reached similar conclusions for Lake Wabamun. Similarly, records of preserved sedimentary microbial pigments from three closed-basin lakes located within the Palliser Triangle (Vinebrooke et al. 1998) and four lakes from the Qu'Appelle Valley (Dixit et al. 2000) revealed high inherent levels of production extending back several centuries.

However, there is accumulating paleoecological evidence that eutrophication of prairie lakes has accelerated since the mid-20th century. Blais et al. (2000) found that Lake Isle and Lac Ste. Anne had undergone recent increases in eutrophication. Similarly, Hall et al. (1999) and Dixit et al. (2000) showed that resource use (cropland area, livestock biomass) and urbanization (nutrients in sewage) were the key drivers of recent increases in algal biomass in lakes of the Qu'Appelle Valley drainage system. Intensification of agriculture and urbanization of the catchment surrounding Lac Saint-Augustin during the 20th century also resulted in eutrophication-induced shifts in diatoms and major increases in sedimentary pigment and nutrient concentrations (Pienitz et al. 2006). Neufeld (2005) documented that phosphorus inputs per unit area of catchment to Lac la Biche from pastures and cropland were approximately double the areal inputs from forested catchments in the area. Moser et al. (2002) and Hazewinkel (2006) present evidence that airborne nutrient sources may also contribute to the eutrophication of prairie lakes. Thus, both our study and several others document that nutrient inputs to lakes have increased greatly throughout the western prairies in the past few decades. Similar results were reported for Lake Winnipeg (Kling 1998). In addition to increased nutrient inputs, Schindler (2006) notes that increased water residence times of lakes resulting from recent warming and drought are likely to contribute to eutrophication by causing increased retention of nutrients in lakes.

Recent eutrophication, even in naturally eutrophic lakes, also appears to be common and widespread in other parts of the world. For example, Rasanen et al. (2006) report the further eutrophication of naturally eutrophic lakes in Finland. Umbanhowar et al. (2003) report recent hypereutrophication of Lake Volney, Minnesota, USA, resulting from livestock culture in the catchment. Reavie et al. (2000) report that of 11 naturally eutrophic lakes in British Columbia, Canada, seven had become more eutrophic as the result of recent human activity. Together, these results suggest that declining water quality accompanying human activity is widespread, despite our advances in knowledge of preventing and reversing eutrophication. When reliable long-term monitoring is not available, multiproxy paleolimnological studies can be used to deduce lake history from the sedimentary record, as we have shown here.

Climate change since 1970 has reduced lake levels and outflow volumes, increased summer surface temperatures, and increased the salinity of lakes in the Canadian prairies (Vinebrooke et al. 1998; Schindler et al. 2004). In some cases, the result has been the proliferation of filamentous benthic cyanobacteria and green algae, even without increases in phosphorus loading. Therefore, climate warming has the potential to synergistically amplify the impacts of human eutrophication on prairie lakes. Such lakes are likely to resist recovery efforts, with internal phosphorus loading persisting for years after external sources have been controlled. Similar conditions have been observed previously (Sondergaard et al. 2001; Schindler 2006).

All of our proxy indicators of eutrophication indicate similar timing for dates of onset and rates, lending credence to the claims of local residents about the condition of the lake. That studies based on a few proxies can result in misinterpretations is well known. For example, Warwick (1980) initially found that interpretation of chironomid remains led to the wrong conclusions about eutrophication in the Bay of Quinte, Ontario. His subsequent inclusions of additional proxies showed that the response of chironomids was confounded by land clearing, which caused massive erosion of silt and clay into the bay, which in turn diluted the increased sedimentation of organic matter resulting from eutrophica- 
tion. Rosén et al. (2001, 2003) found that when several proxies of climate warming were compared, there were inconsistencies between the reconstructions provided by each. They attributed these to the lack of adequate modern analogues for some proxies and the effects of long-distance transport of pollen to their study lakes. They concluded that multiproxy studies leading to a consensus reconstruction are necessary to obtain reliable indications of past conditions in lakes. We agree with their conclusion.

\section{Acknowledgements}

Brian Parker and Margaret Foxcroft helped with the manuscript and figure preparation. Tom Maccagno, Mike Sullivan, and Chris Davis supplied data on the history and fisheries of Lac la Biche. Suzanne Bayley, Stephanie Neufeld, Jay White, and a group of volunteers from the community of Lac La Biche assisted with winter coring. Reviews by Thomas Whitmore and an anonymous reviewer greatly improved the manuscript. Our study was funded by a grant from Lakeland County, Alberta, and a Natural Sciences and Engineering Research Council of Canada Gold Medal Supplement to D.W.S.

\section{References}

Blais, J.M., Duff, K.E., Schindler, D.W., Smol, J.P., Leavitt, P.R., and Agbeti, M.D. 2000. Recent eutrophication histories of Lac Ste. Anne and Lake Isle, Alberta, Canada, using paleolimnological methods. Lake Reserv. Manage. 16: 292-304.

Bradbury, J.P. 1975. Diatom stratigraphy and human settlement in Minnesota. Geol. Soc. Am. Spec. Pap. No. 171.

Conley, D., and Schelske, C.L. 2001. Biogenic Silica. In Tracking environmental change using lake sediments. Vol. 3. Terrestrial, algal and siliceous indicators. Edited by J.P. Smol, W.M. Last, and H.J.B. Birks. Kluwer Academic Publishers, Dordrecht, the Netherlands. pp. 281-293.

Cumming, B.F., Wilson, S.E., Hall, R.I., and Smol, J.P. 1995. Diatoms from British Columbia (Canada) lakes and their relationship to salinity, nutrients and other limnological variables. In Bibliotheca Diatomologica. Band 31. J. Cramer, Stuttgart, Germany.

Dixit, A.S., Hall, R.I., Leavitt, P.R., Quinlan, R., and Smol, J.P. 2000. Effects of sequential depositional basins on lake response to urban and agricultural pollution: a paleoecological analysis of the Qu'Appelle Valley, Saskatchewan, Canada. Freshw. Biol. 43: 319-337. doi:10.1046/j.1365-2427.2000.00516.x.

Douglas, M.S.V., and Smol, J.P. 1999. Freshwater diatoms as indicators of environmental change in the High Arctic. In The diatoms: applications for the environmental and earth sciences. Edited by E.R. Stoermer and J.P. Smol. Cambridge University Press, Cambridge, UK. pp. 227-244.

Forbes, J.R., and Hickman, M. 1981. Paleolimnology of shallow lakes in central Alberta, Canada. Int. Rev. Gesamten Hydrobiol. 66: 863-888. doi:10.1002/iroh.19810660610.

Hall, R.I., Leavitt, P.R., Quinlan, R., Dixit, A.S., and Smol, J.P. 1999. Effects of agriculture, urbanization, and climate on water quality in the northern Great Plains. Limnol. Oceanogr. 44: 739-756.

Hann, B.J. 1989. Methods in quaternary ecology. No. 6. Cladocera. Geoscience Canada, 16: 17-26.

Hazewinkel, R.R.O. 2006. A paleolimnological assessment of environmental change in eight northeastern Alberta lakes. M.Sc. thesis, Department of Earth and Atmospheric Sciences, University of Alberta, Edmonton, Alta.

Hickman, M., and Klarer, D.M. 1981. Paleolimnology of Lake Isle,
Alberta, Canada (including sediment chemistry, pigments and diatom stratigraphy). Arch. Hydrobiol. 91: 490-508.

Hickman, M., Schweger, C.E., and Habgood, T. 1984. Lake Wabamun, Alta.: a paleoenvironmental study. Can. J. Bot. 62: 14381465. doi:10.1139/b84-194.

Jeppesen, E., Jensen, J.P., Søndergaard, M., Lauridsen, T., and Landkildehus, F. 2000. Trophic structure, species richness and biodiversity in Danish lakes: changes along a phosphorus gradient. Freshw. Biol. 45: 201-218. doi:10.1046/j.1365-2427.2000. 00675.x.

Kling, H.J. 1998. A summary of past and recent plankton of Lake Winnipeg, Canada, using algal fossil remains. J. Paleolimnol. 19: 297-307. doi:10.1023/A:1007990217568.

Krammer, K., and Lange-Bertalot, H. 1986-1991. Bacillariophyceae. In Süsswasserflora von Mitteleuropa 2/1-4. Edited by H. Ettl, J. Gerloff, H. Heynig, and D. Mollenhauer. G. Fischer Verlag, Stuttgart, Germany.

Mitchell, P. 2001. Lac la Biche: water quality and phosphorus sources. P. Mitchell Environmental Consulting, Edmonton, Alberta.

Mitchell, P., and Prepas, E. 1990. Atlas of Alberta lakes. University of Alberta Press, Edmonton, Alberta.

Mortlock, R.A., and Froelich, P.N. 1989. A simple method for the rapid determination of biogenic opal in pelagic marine sediments. Deep-Sea Res. 36: 1415-1426. doi:10.1016/01980149(89)90092-7.

Moser, K.A., Smol, J.P., MacDonald, G.M., and Larsen, C.P.S. 2002. 19th century eutrophication of a remote boreal lake: a consequence of climate warming? J. Paleolimnol. 28: 269-281. doi:10.1023/A:1021635024757.

Moser, K.A., Smol, J.P., and MacDonald, G.M. 2004. Ecology and distribution of diatoms from boreal forest lakes in Wood Buffalo National Park, northern Alberta and the Northwest Territories, Canada. Academy of Natural Sciences of Philadelphia Special Publication No. 22. pp. 1-59.

Neufeld, S.D. 2005. Effects of catchment land use on nutrient export, stream water chemistry, and macroinvertebrate assemblages in boreal Alberta. M.Sc. thesis, Department of Biological Sciences, University of Alberta, Edmonton, Alta.

Patrick, R., and Reimer, C.W. 1966. The diatoms of the United States exclusive of Alaska and Hawaii. Academy of Natural Sciences of Philadelphia Monograph No. 13. Vol. 1.

Patrick, R., and Reimer, C.W. 1975. The diatoms of the United States exclusive of Alaska and Hawaii. Academy of Natural Sciences of Philadelphia Monograph No. 13. Vol. 2. Part 1.

Pienitz, R., Roberge, K., and Vincent, W.F. 2006. Three hundred years of human-induced change in an urban lake: paleolimnological analysis of Lac Saint-Augustin, Quebec City, Canada. Can. J. Bot. 84: 303-320. doi:10.1139/B05-152.

Prepas, E.E., and Trew, D.O. 1983. Evaluation of the phosphoruschlorophyll relationship for lakes off the Precambrian Shield in western Canada. Can. J. Fish. Aquat. Sci. 40: 27-35. doi:10. 1139/f83-163.

Prepas, E.E., and Trimbee, A.M. 1988. Evaluation of indicators of nitrogen limitation in deep prairie lakes with laboratory bioassays and limnocorrals. Hydrobiologia, 159: 269-276. doi:10. 1007/BF00008240.

Prepas, E.E., and Vickery, J. 1984. Seasonal changes in total phosphorus and the role of internal loading in western Canadian lakes. Verh. Int. Verein. Limnol. 22: 303-308.

Rasanen, J., Kauppila, T., and Salonen, V.P. 2006. Sediment-based investigation of naturally or historically eutrophic lakes implications for lake management. J. Environ. Manage. 79: 253-265. doi:10.1016/j.jenvman.2005.08.001. PMID:16256266. 
Reavie, E.D., Smol, J.P., Sharpe, I.D., Westenhofer, L.A., and Roberts, A.M. 2000. Paleolimnological analyses of cultural eutrophication patterns in British Columbia lakes. Can. J. Bot. 78: 873-888. doi:10.1139/cjb-78-7-873.

Riedinger-Whitmore, M.A., Whitmore, T.J., Smoak, J.M., Brenner, M., Moore, A., Curtis, J., and Schelske, C.L. 2005. Cyanobacterial proliferation is a recent response to eutrophication in many Florida lakes: a paleolimnological assessment. Lake Reserv. Manage. 21: 423-425.

Rosén, P., Segerström, U., Eriksson, L., Renberg, I., and Birks, H.J.B. 2001. Holocene climatic change reconstructed from diatoms, chironomids, pollen and near-infrared spectroscopy at an alpine lake (Sjuodjijaure) in northern Sweden. Holocene, 11: 551-562. doi:10.1191/095968301680223503.

Rosén, P., Segerström, U., Eriksson, L., and Renberg, I. 2003. Do diatom, chironomid and pollen records consistently infer Holocene July air temperature? A comparison using sediment cores from four alpine lakes in northern Sweden. Arct. Antarct. Alp. Res. 35: 279-290. doi:10.1657/1523-0430(2003) 035[0279:DDCAPR]2.0.CO;2.

Schelske, C.L., Stoermer, E.F., and Kenney, W.F. 2006. Historic low-level phosphorus enrichment in the Great Lakes inferred from biogenic silica in the sediment. Limnol. Oceanogr. 51: 728-748.

Schindler, D.W. 2006. Recent advances in the understanding and management of eutrophication. Limnol. Oceanogr. 51: 356-363.

Schindler, D.W., and Comita, G.W. 1972. The dependence of primary production upon physical and chemical factors in a small senescing lake, including the effects of complete winter oxygen depletion. Arch. Hydrobiol. 69: 413-451.

Schindler, D.W., Anderson, A.-M., Brzustowski, J., Donahue, W.F.,
Goss, G., Nelson, J., St. Louis, V., Sullivan, M., and Swanson, S. 2004. Lake Wabamun: a review of scientific studies and environmental impacts. Prepared for the Minister of Alberta Environment, Edmonton, Alberta. Publ. No. T769.

Sondergaard, M.J., Jensen, J.P., and Jeppesen, E. 2001. Retention and internal loading of phosphorus in shallow eutrophic lakes. The Scientific World, 1: 427-442.

Stauffer, R.E. 1985. Relationships between phosphorus loading and trophic state in calcareous lakes of southeast Wisconsin. Limnol. Oceanogr. 30: 123-145.

Stauffer, R.E., and Armstrong, D.E. 1984. Lake mixing and its relationship to epilimnetic phosphorus in Shagawa Lake, Minnesota. Can. J. Fish. Aquat. Sci. 41: 57-69. doi:10.1139/f84-006.

Umbanhowar, C.E., Engstrom, D.R., and Bergman, E.C. 2003. Reconstructing eutrophication and phosphorus loading for Lake Volney, Minnesota: combining lake sediments and land-use history to establish "natural" baselines for management and restoration. Lake Reservior Manage. 19: 364-372.

Vinebrooke, R.D., Hall, R.I., Leavitt, P.R., and Cumming, B.F. 1998. Fossil pigments as indicators of phototrophic response to salinity and climatic change in lakes of western Canada. Can. J. Fish. Aquat. Sci. 55: 668-681. doi:10.1139/cjfas-55-3-668.

Warwick, W.F. 1980. Chironomidae (Diptera) responses to 2800 years of cultural influence: a palaeolimnological study with special reference to sedimentation, eutrophication, and contamination processes. Can. Entomol. 112: 1193-1238.

Wolfe, A.P. 1997. On diatom concentrations in lake sediments: results of an inter-laboratory comparison and other experiments performed on a uniform sample. J. Paleolimnol. 18: 261-266. doi:10.1023/A:1007937300347. 